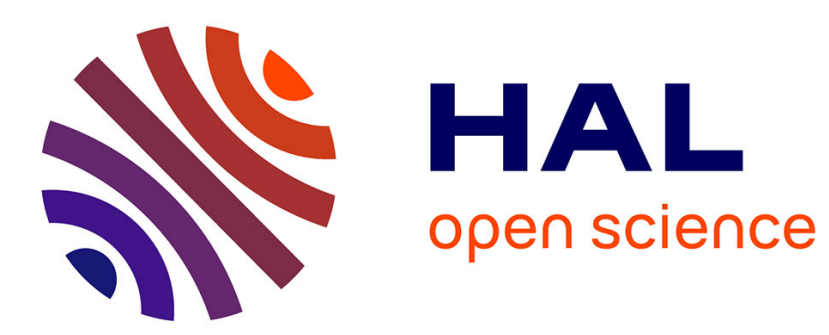

\title{
IONIC CONDUCTIVITY MEASUREMENTS OF BARIUM FLUORIDE SINGLE CRYSTALS
}

\author{
V. Carr, A. Chadwick, D. Figueroa
}

\section{To cite this version:}

V. Carr, A. Chadwick, D. Figueroa. IONIC CONDUCTIVITY MEASUREMENTS OF BARIUM FLUORIDE SINGLE CRYSTALS. Journal de Physique Colloques, 1976, 37 (C7), pp.C7-337-C7-341. 10.1051/jphyscol:1976778 . jpa-00216938

\section{HAL Id: jpa-00216938 https://hal.science/jpa-00216938}

Submitted on 1 Jan 1976

HAL is a multi-disciplinary open access archive for the deposit and dissemination of scientific research documents, whether they are published or not. The documents may come from teaching and research institutions in France or abroad, or from public or private research centers.
L'archive ouverte pluridisciplinaire HAL, est destinée au dépôt et à la diffusion de documents scientifiques de niveau recherche, publiés ou non, émanant des établissements d'enseignement et de recherche français ou étrangers, des laboratoires publics ou privés. 


\title{
IONIC CONDUCTIVITY MEASUREMENTS OF BARIUM FLUORIDE SINGLE CRYSTALS
}

\author{
V. M. CARR, A. V. CHADWICK \\ University Chemical Laboratory, University of Kent, Canterbury, Kent, U. K. \\ and
}

D. R. FIGUEROA

Departamento de Fisica, Universidad Simon Bolivar, Caracas, Venezuela

\begin{abstract}
Résumé. - Nous avons mesuré la conductivité avec une tension alternative des monocristaux de $\mathrm{BaF}_{2}$ jusqu'à $1336 \mathrm{~K}$. Aux températures plus élevées nous avons observé les effets de la polarization, peut-être le résultat d'une réaction des cristaux avec l'atmosphère dans le dispositif. Les énergies des défauts dérivés du domaine de température moins élevé s'accordent bien avec ceux que Barsis et Taylor $[27,28]$ ont obtenu. L'effet de la transition de phase aux hautes températures sur la conductivité est discuté.
\end{abstract}

Abstract. - We have measured the a. c. conductivity of pure $\mathrm{BaF}_{2}$ single crystals up to $1336 \mathrm{~K}$. At the higher temperatures we observed polarisation effects possibly due to a reaction of the crystal with the atmosphere in the cell. The defect energies derived from the low temperature region agree well with those obtained by Barsis and Taylor $[27,28]$. The effect of the high temperature phase transition on the conductivity is discussed.

Introduction. - Investigations of the alkaline earth fluorides, $\mathrm{CaF}_{2}, \mathrm{SrF}_{2}, \mathrm{BaF}_{2}$, have shown that the $\mathrm{F}^{-}$ ion has a relatively high mobility and the predominant point defects are of the anti-Frenkel type [1]. The relative concentrations of $\mathrm{F}^{-}$ion vacancies and interstitial $\mathrm{F}^{-}$ions can be altered in the usual way by doping with aliovalent ions. An unusual feature of these materials, and this appears to be a peculiarity of compounds with the fluorite structure, is that they will tolerate high concentrations of interstitial anions. Thus trivalent metal fluorides can be dissolved in them in large quantities (up to 50 mole per cent at the melting point [2]), the cation being incorporated substitutionally and the excess anions interstitially. Another special feature of the fluorite compounds is that they exhibit a broad specific heat anomaly at high temperatures which is similar to the lambda-type behaviour associated with order-disorder transitions $[3,4]$. This has been interpreted as a transition from the normal fluorite lattice, $\mathrm{AB}_{2}$, at low temperatures to a disordered state in which the $B$ ion is distributed between normal anion and interstitial sites [3]. The transition has also been investigated by light-scattering [5] and neutron diffraction [6] techniques. One cause of fast ion conduction in solids, sometimes termed superionicity, is a highly disordered lattice [7]. Thus there is interest in the fluorites as model systems in which to study this phenomenon [8].
Information on ionic transport, i. e. defect formation energies, migration energies and diffusion mechanisms, is usually obtained from measurements of the ionic conductivity and self-diffusion in single crystals over a wide temperature range [9-11]. For the alkaline earth fluorides a major problem in conductivity measurements is the high reactivity with oxygen and water vapour $[12,13]$. Conductivity measurements on alkaline earth fluorides are also hampered by two additional factors ; the sample resistance is low and the sublimation rate is high. On the whole the quality of the reported conductivity for the alkaline earth fluorides has not been sufficiently good to use the computer-fitting methods of obtaining defect parameters developed for the alkali halides (see for example reference [14]).

Self-diffusion measurements of $\mathrm{F}^{-}$ions in alkaline earth fluorides are beset by special difficulties. The radio-isotope ${ }^{18} \mathrm{~F}$ has an inconveniently short half-life of 1.7 hours and has only been used in one study of these materials [15]. Another technique for studying diffusion is nuclear magnetic resonance $N . M . R$. relaxation time measurements. The potential of this technique has been increased by recent theoretical developments in the methods of evaluating precise diffusion coefficients from the measured relaxation times [16]. However, as the recent study of $\mathrm{BaF}_{2}$ indicated there are still problems of detail with the N. M. R. which have to be resolved [17]. The N. M. R. 
activation energies in alkaline earth fluorides doped with paramagnetic trivalent metal fluorides are unreliable $[18,19,20]$. The pulsed field gradient N. M. R. measurements of $F^{-}$diffusion in $\mathrm{BaF}_{2}$ reported at this conference shows great promise for the study of alkaline earth fluorides [21].

The specific heat anomaly due to the transition peaks at about $1235 \mathrm{~K}$ in $\mathrm{BaF}_{2}$ [4] and there has only been one conductivity study that exceeds this temperature [22]. Conductivity studies have been made across the transition in $\mathrm{CaF}_{2}, \mathrm{SrF}_{2}$ [23] and in two other materials with the fluorite structure, $\mathrm{SrCl}_{2}$ [23] and $\mathrm{PbF}_{2}$ [24]. We have extended our earlier conductivity measurements in $\mathrm{BaF}_{2}$ to $1336 \mathrm{~K}$ in an attempt to obtain precise results in the region of the transition. The results of these experiments and some of the experimental difficulties we encountered are reported in this paper.

Experimental. - The $\mathrm{BaF}_{2}$ crystals were grown from powder by the Stockbarger technique using graphite crucibles (Ultra Carbon, UF4S grade) and a radio-frequency induction furnace [17]. The samples used in the present experiments were cylindrical rods typically $0.3 \mathrm{~cm}$ diameter $\times 1.5 \mathrm{~cm}$ long. Graphite electrodes were applied to ends of the samples by painting on a dilute suspension of colloidal graphite in iso-propyl alcohol (Acheson DAG 502).

The conductivity cell was made of silica with a platinum electrode-thermocouple system and was essentially the same as that described by Allnatt and Jacobs $[25,17]$. A. c. conductivities were measured at $1592 \mathrm{~Hz}$ (Wayne-Kerr B641 bridge), $20 \mathrm{kHz}$ and $50 \mathrm{kHz}$ (Wayne-Kerr B221 bridge, Wayne-Kerr S121 signal generator and an oscilloscope detector) and $500 \mathrm{kHz}$ (Hewlett-Packard 4815A R. F. vector impedance meter). The conductivity measurements were made in a dynamic vacuum. In preliminary experiments, where the sample was maintained in a stream of purified nitrogen, we found penomena of the kind reported by Ure [12] ; oxygen or water contamination resulted in a highly conductive coating of the sample after heating to high temperatures and the surfaces of the sample were opaque. At the end of the conductivity runs reported here the samples were clear and transparent and the pumping system and run procedure merit further description.

The apparatus was assembled with the following pumping sequence ; (i) a fore-line system (a rotary oil pump, mercury diffusion pump and liquid nitrogen traps), (ii) a mercury diffusion pump, (iii) a U-trap, (iv) a U-trap filled with molecular sieve, (v) the conductivity cell. After loading, the cell was pumped for 48 hours with the fore-line system. During this period the U-traps were baked. The mercury diffusion pump (ii) was then turned on, the U-traps immersed in liquid nitrogen and the cell pumped for a futher 24 hours. After this period the ionization gauge at the top of the cell (the farthest part of the cell from the pumps) indicated a pressure of $10^{-6}$ torr. The cell was then heated and conductivity measurements commenced. In the early stages of heating (up to $600 \mathrm{~K}$ ) the vacuum temporarily deteriorated to $10^{-5}$ torr due to de-gassing of the cell. The furnace used was wound in section so that temperature gradients along the sample could be minimized and the temperature was controlled with a proportional controller to $\pm 0.2 \mathrm{~K}$. Conductivity measurements were taken at approximately $10 \mathrm{~K}$ intervals and at each temperature of measurement the system was allowed to reach equilibrium for at least $15 \mathrm{~min}$. The lead corrections to the measured conductivities were estimated in a blank run.

Results. - Initially detailed conductivity measurements were made on a pure crystal, sample 1 , in the temperature range $450 \mathrm{~K}$ to $1000 \mathrm{~K}$. The conductivity showed no measurable frequency dependence, was reproducible on thermal cycling and in good agreement with our previous data [17]. The extension of our measurements to higher temperatures revealed some complex effects.

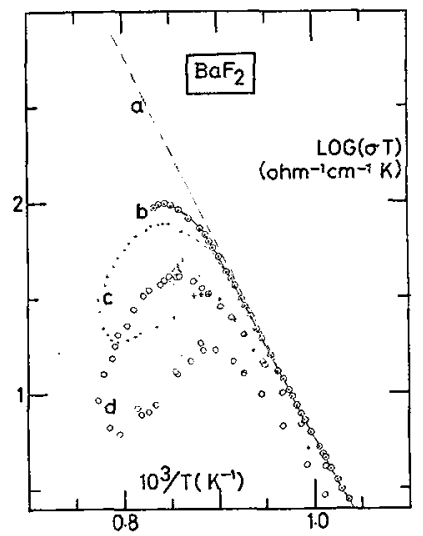

Fig. 1. - The $1592 \mathrm{~Hz}$ conductivity curves for sample 1 at high temperatures. (a) Extrapolated line from low temperatures ; $(b),(c)$ and $(d)$ are the results for the first, second and third heating-cooling cycles, respectively. In curves $(c)$ and $(d)$ the conductivities were higher on the initial increasing temperature portion of the cycle.

In figure 1 we have plotted only the $1592 \mathrm{~Hz}$ measurements at high temperatures for sample 1 in the form $\log \sigma T$ versus $10^{3} / T$. The conductivity has been corrected for the resistance of the measuring leads and sublimation. On the first heating the plot shows a negative deviation from a line extrapolated from lower temperatures and passes through a maximum. In the later heating-cooling cycles the plot exhibits a loop, the conductivity values being lower on cooling than on heating. The apparent symmetry of the loops arises because the measurements were taken at regular intervals of time. 


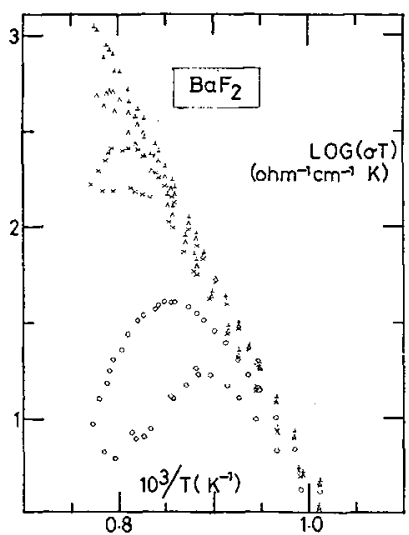

FIG. 2. - The conductivity curves for sample 1 during one heating-cooling cycle. The measuring frequencies were : $\perp 500 \mathrm{kHz}, \wedge 50 \mathrm{kHz}, \times 20 \mathrm{kHz}, 01592 \mathrm{~Hz}$.

The conductivity results for sample 1 at all four measuring frequencies during one of the abovementioned heating-cooling cycles is shown in figure 2. Similar loops are seen in the results for the three lower measuring frequencies. The slight deviation seen in the $500 \mathrm{kHz}$ results is predominantly due to sublimation and measurements at this frequency were not affected by thermal cycling.

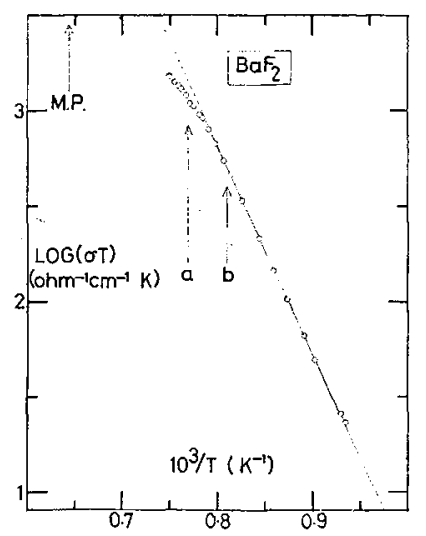

FIG. 3. - The $500 \mathrm{kHz}$ conductivity curve for sample 3 at high temperatures. The data includes a correction for the lead resistance. $(a)$ and $(b)$ are the transition temperatures from neutron diffraction [6] and specific heat [4] data.

Similar results to those described above were found in two other samples. For sample 3 the first heatingcooling cycle was taken to a maximum temperature of $1336 \mathrm{~K}$. The $500 \mathrm{kHz}$ measurements for the heating section of this cycle are shown in figure 3 . In this figure the data points have been corrected, with a reasonable precision, for the lead resistance. In figure 4 , we have plotted the raw data in the highest temperature region along with the estimates of the corrections necessary to

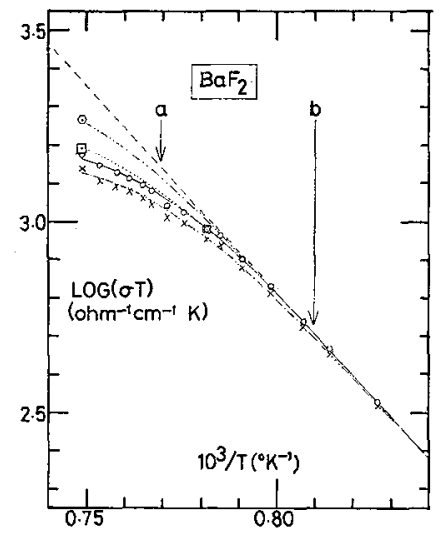

FIG. 4. - The $500 \mathrm{kHz}$ conductivity results for sample 3 shown on a large scale. Various corrections have been applied to the raw data ; (i) lead correction, (ii) extrapolation of the conductivity to infinite frequency, (iii) sublimation correction, $x$. raw data, 0 raw data + (i), $\bullet$ raw data + (i) $+($ ii $), \diamond$ raw data + (i) + (ii) + (iii).

obtain the true conductivity. There is a deviation of the true conductivity from a line extrapolated through the points below $1250 \mathrm{~K}\left(10^{3} / T=0.8\right)$ and at $1336 \mathrm{~K}$ the conductivity is $\sim 20 \%$ below the predicted value.

Low temperature measurements, taken after the high temperature cycles, indicated that the crystals had become lightly doped. Although the lengths of the sample had not changed during the runs the diameter was considerably reduced by the sublimation.

Discussion. - We have not attempted a quantitative explanation of the observed polarization effects since they are not intrinsic properties of the crystals. A possible qualitative interpretation is that the samples are reacting with traces of oxygen and water vapour in the cell and a thin oxygen containing layer is continuously building up on the surface which under the electrodes could block the charge carriers [13]. This would explain the frequency dependence, the loops in figure 1 and the persistence of the effects in consecutive heatingcooling cycles. In future discussion we will assume that the conductivity intrinsic to the crystal would be that obtained by extrapolating the measurements for a first heating cycle to infinite frequency. This conductivity for sample 1 is shown in figure 5 along with data for doped crystals from our previous work [17].

For the purpose of discussion we will divide the plot of $\log \sigma T$ versus $10^{3} / T$ for pure $\mathrm{BaF}_{2}$, figures 3,4 and 5 , into four temperature regions; (I) $10^{3} / T>1.25$, the plot is remarkably linear with apparent activation energy of $1.52 \pm 0.01 \mathrm{eV}$, (II) $10^{3} / T<1.25$ and $>$ $0.90 \mathrm{eV}$, the plot shows a gentle, upward curvature, (III). $10^{3} / T<0.90$ and $>0.80$, the plot is roughly linear with an apparent activation energy of $\sim 2.1 \mathrm{eV}$ (sample $1=2.10 \mathrm{eV}$, sample $3=2.14 \mathrm{eV}$ ), (IV) $10^{3} / T<0.80$ the slope of the plot is decreasing. We realise that such divisions are somewhat arbitrary 


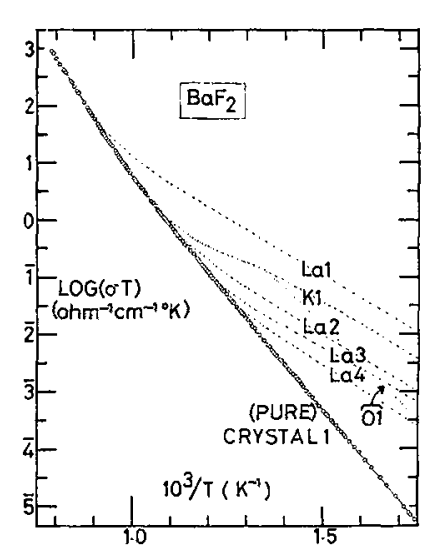

FIG. 5. - The complete conductivity curve for sample 1, The data for doped crystals [17] is indicated by the broken lines; La $1,2,3$ and 4 contain $1.2 \times 10^{4}, 920, \sim 500$ and 285 p. p. m. $\mathrm{La}^{3+}$ respectively; $\mathrm{K} 1$ contains 400 p. p. m. $\mathbf{K}^{+}$; and $\mathrm{O} 1$ contains an unknown concentration of oxygen.

and only provide a rough analysis, however, they are useful in comparing our work with previous studies. Barsis and Taylor [27, 28] made measurements up to $10^{3} / T=0.85$ and divided the intrinsic region into two roughly linear region with apparent activation energies equal to $1.49 \mathrm{eV}\left(10^{3} / T>1.12\right)$ and $1.64 \mathrm{eV}\left(10^{3} / T<1.12\right)$. In their earlier, less detailed study of $\mathrm{BaF}_{2}$, they reported the intrinsic region as being linear up to the limit of their measurements, $10^{3} / T=0.7$ with an apparent activation energy of $1.64 \mathrm{eV}$ [22]. Fielder's measurements were made up to $10^{3} / T=0.855$ and he divided the intrinsic region of his plot of $\log \sigma$ versus $10^{3} / T$ into three regions, $10^{3} / T>1.2,1.2<10^{3} / T>1.06$ and $10^{3} / T<1.06[26]$. Bollmann [29] reported a linear intrinsic region for $\mathrm{BaF}_{2}$, his upper temperature limit being $10^{3} / T=0.85$, the apparent absence of curvature in his data could be due to a lack of a sufficient density of data points. It is significant that Bollmann's reported apparent activation energy lies between those for Barsis and Taylor's two regions and our regions $I$ and II.

Using the assumption that the dominant mobile defects in region $I$ are $F^{-}$vacancies and the doped crystal data we have evaluated the enthalpies of antiFrenkel defect fromation, $h_{\mathrm{F}}, \mathrm{F}^{-}$vacancy migration, $h_{\mathrm{mv}}$, and $\mathrm{F}^{-}$interstitial migration, $h_{\mathrm{mi}}$. Our values are $h_{\mathrm{F}}=1.91 \pm 0.03 \mathrm{eV}, h_{\mathrm{mv}}=0.56 \pm 0.02 \mathrm{eV}$, and $h_{\mathrm{mi}}=0.76 \pm 0.01 \mathrm{eV}[17]$. These values are in good agreement with those obtained by Barsis and Taylor $[27,28]$ and from N. M. R. measurements [17].

Part of the curvature in region II is expected to be due to the increasing contribution from the $\mathrm{F}^{-}$interstitial ions. However, the limiting slope in region III, $2.1 \mathrm{eV}$, is higher than that predicted for conduction dominated by $\mathrm{F}^{-}$ions diffusing by the interstitialcy mechanism, i. e. $\sim 1.72 \mathrm{eV}$. Our preliminary attempts to fit the results with a least-squares program [14], based on a model of $\mathbf{F}^{-}$vacancy and interstitial diffusion, were unsuccessful. The poor fit at high temperatures suggested the need to incorporate more processes into the model. The inclusion of cation diffusion would probably not improve the situation $[30,31]$, although theoretical calculations suggest a direct interstitial mechanism of $\mathrm{F}^{-}$diffusion may be important [32]. The generation of anti-Frenkel defects due to the onset of the phase transition, beginning at $\sim 1000 \mathrm{~K}$, may also be important in regions II and III. The decreasing apparent activation energy in region IV is probably due to the fact that the defect concentration here is so high that the mechanism of conduction is that of a highly disordered solid and could only be interpreted on such a model [7, 8]. It is arguable that our evidence for region IV is slight, however, if such a decrease in the activation energy did not occur and region III continued on up to the melting point then the predicted specific conductivity of the melt would be $\sim 20 \Omega^{-1} \mathrm{~cm}^{-1}$. This is much higher than the melt values for $\mathrm{CaF}_{2}\left(3.56 \Omega^{-1} \mathrm{~cm}^{-1}\right.$ [33] $)$ and other fluorites [23]. There is also evidence for a region of lower apparent activation energy in the N.M.R. results at similar temperatures [21].

Only a few of the conductivity studies of fluorites in the region of the phase transition are on welldefined samples. The highest temperature region of Fielder's data for $\mathrm{BaF}_{2}$ crystals corresponds roughly with our region III, although we feel he was incorrect in interpreting this as an anomalous electrode effect due to the use of platinum [26]. In $\mathrm{PbF}_{2}$ regions III and IV have been observed [24, 34, 35]. Experiments on $\mathrm{SrCl}_{2}$ crystals have revealed a region III but measurements have not been made to a high enough temperature to show if a region IV exists $[36,37]$. For both of these materials, as in $\mathrm{BaF}_{2}$, region III has an anomalously high activation energy. The work on $\mathrm{CaF}_{2}$ and $\mathrm{SrF}_{2}$ samples obtained by freezing the melts was aimed at obtaining qualitative information [23] and it shows effects similar to those we observed. It is worth noting that the neutron data [6] indicates that there is not complete disordering of the fluoride sublattice at the phase transition in $\mathrm{SrF}_{2}$ and $\mathrm{BaF}_{2}$. The extension of these studies and more information on the defect concentrations is needed for a better understanding of the conductivity results.

Conclusions. - We have obtained conductivity results on single crystals of $\mathrm{BaF}_{2}$ up to $1336 \mathrm{~K}$ to which a detailed analysis should be applicable.

The large polarisation affects that we observed may be peculiar to $\mathrm{BaF}_{2}$ since other workers have found this material particularly reactive [23], although some preliminary work on $\mathrm{SrCl}_{2}$ crystals has shown similar effects [37]. This points to the need for special care in the conductivity measurements on fluorites and the use of a wide frequency range in a. c. measurements. The extension of measurements on $\mathrm{BaF}_{2}$ to higher temperatures will be severely hampered by the high volatility of this system. 
Acknowledgments. - We wish to thank Professor P. W. M. Jacobs for the provision of the leastsquares program and his general help and advice with this project. We also thank Drs. J. H. Strange and R. E. Gordon for numerous helpful discussions. We acknowledge the assistance of the Science Research Council in the form of an equipment grant to A. V. C. and a fellowship to V. M. C. Financial support to D. R. F. from I. V. I. C. Venezuela is also gratefully acknowledged.

\section{References}

[1] Lidrard, A. B., in Crystals with the Fluorite Structure ed. Hayes, W. (Clarendon Press, Oxford) 1974, 101.

[2] Ippolitov, E. G., Garashina, L. S. and MaklasKLOV, A. G., Inorg. Mater 3 (1967) 59.

[3] Dworkin, A. S. and Bredig, M. A., J. Phys. Chem. 72 (1968) 1277 .

[4] Belosludov, V. R., EFremova, R. I. and Matizen, E. V., Sov. Phys. Solid State [English Translation] 16 (1974) 847.

[5] Harley, R. T., Hayes, W., Rushworth, A. J. and Ryan, J. F., J. Phys. C 8 (1975) 1530.

[6] Thomas, M. W., Chem. Phys. Lett. 40 (1976) 111.

[7] See, for example, Fast Ion Transport in Solids ed. van Gool, W., (North-Holland, Amsterdam) 1973.

[8] O'KeEFFe, M., in Fast Ion Transport in Solids ed. van Gool, W. (North-Holland, Amsterdam) 1973, 233.

[9] Lidiard, A. B., in Handbuch der Physik Vol. XX, (Springer-Verlag, Berlin) 1957, 246.

[10] BARR, L. W. and Lidiard, A. B., in Physical chemistry, an advanced treatise, Vol. X (Academic Press, New York) 1970, 151.

[11] CORISH, J. and $\mathbf{J}_{\mathrm{ACOBS}}, \mathrm{P}$. W. M. in Surface and defect properties of solids, Vol. II, (The Chemical Society, London) 1973.

[12] URE, R. W., J. Chem. Phys. 26 (1957) 1363.

[13] Frankin, A. D., Marzullo, S. and Wachtman, J. B., J. Res. Nat. Bur. Standards 71A (1967) 355.

[14] JACoks, P. W. M. and Pantelis, P., Phys. Rev. B 4 (1971) 3757.

[15] MATzKe, H., J. Mater. Sci. 5 (1970) 831.

[16] Wolf, D., Phys. Rev. 10 (1974) 2710 and 2724.

[17] Frgueroa, D. R., Chadwick, A. V. and Strange, J. H., to be published.
[18] Lysiak, R. J. and Mahendroo, P. P., J. Chem. Phys. 44 (1966) 4025.

[19] Mnller, J. R. and Mahendroo, P. P., Phys. Rev. 174 (1968) 369.

[20] Knowles, J. T. and Mahendroo, P. P., Phys. Lett. 31A (1970) 385.

[21] Gordon, R. E. and Strange, J. H., J. Physique Colloq. 37 (1976) this issue.

[22] Barsis, E. and TAYlor, A., J. Chem. Phys. 45 (1966) 1154.

[23] Derrington, C. E., Lindner, A. and O'Kreffe, M., J. Solid State Chem. 15 (1975) 171.

[24] Derrington, C. E. and O'KeefFe, M., Nature (Phys. Sci.) 246 (1973) 44.

[25] Allnatt, A. R. and JacoBs, P. W. M., Trans. Faraday Soc. 58 (1962) 116.

[26] Fielder, L., N. A. S. A. Report TN D-3346 (1968)

[27] Barsis, E. and Taylor, A., J. Chem. Phys. 48 (1968) 4357.

[28] Barsis, E. and Taylor, A., J. Chem. Phys. 48 (1968) 4362.

[29] BollmanN, W., Phys. Status Solidi A 18 (1973) 313.

[30] Baker, M. and TAYlor, A., J. Phys. \& Chem. Solids 30 (1969) 1003.

[31] MATZKe, H. and LindNER, R., Z. Naturforsch. 199 (1964) 1178 .

[32] Catlow, C. R. A., D. Phil. thesis, University of Oxford, (1973).

[33] BaAk, T., J. Chem. Phys. 29 (1958) 195.

[34] Benz, R., $Z$. Phys. Chem. (Frankfurt) 95 (1975) 25.

[35] CARR, V. M. and CHADwick, A. V., to be published.

[36] Hood, G. M. and Morrison, J. A., J. Appl. Phys. 38 (1967) 4796.

[37] Saghafian, R., Chadwick, A. V. and Carr, V. M., to be published.

\section{DISCUSSION}

A. L. Laskar. - 1) The hysteresis effect during thermal cycling, frequency effect and the decrease of the conductivity with time have been attributed to the formation of oxide layer on $\mathrm{BaF}_{2}$ (blocking layer). Could you elaborate this little more.

2) Does one expect to see the same effects in $\mathrm{CaF}_{2}$ as studied by P. W. M. Kacobs ?

A. V. Chadwick. - 1) We have said a little more on this point in the paper. Our main aim was to determine the true conductivity of $\mathrm{BaF}_{2}$ and we did not try to study these effects in detail, indeed such a study would be difficult.

2) I would expect similar effects in $\mathrm{CaF}_{2}$. Prof. Jacobs (private communication) in his study of $\mathrm{CaF}_{2}$ found that the conductivity decreased with time at the highest temperatures of his measurements. This is consistent with our observations.

A. Rahman. - Presence of conductivity loop was also observed by us i. e. a sort of hysteresis of $\Delta R$ and $\Delta T$ was observed. It would be interesting to know the cause of its existence.
A. V. Chadwick. - I must emphasize that the effects we see are not really hysteresis. The conductivity is irreproducible and the loops only appear to be symmetrical due to the way in which the measurements were taken. Thus they may not be related to the effects you observe.

R. Capelletti. -- Also during ITC measurements on $\mathrm{CdF}_{2}$ doped with $\mathrm{Eu}^{+++}$annealed at moderately high temperatures, we had spurious effects. For instance the loss or the decrease of the ITC signal due to the formation of a conductive yellow film on the sample $\left(^{*}\right)$.

However chemical etching of the sample removed the film and caused the recovery of the ITC signal. Have you tried to perform an etching on your samples?

A. V. ChaDwick. - No, but it is an interesting idea and we will do the etching experiment.

(*) Capelleti R., Fermi F., Schiavi R., " Rols of solution and precipitation phenomena on ITC spectra due to Rare EarthFluorine Interstitial complexes in $\mathrm{CdF}_{2}: \mathrm{Eu}$ 》 - Proc. of Internat. Symp. on Electrets, Charge Storage and Transport. in Dielectrics. São Carlos (Carlos (Brasil) Sept. 1975. 